\title{
Morfologia do fruto, da semente e morfo-anatomia da plântula de Vitex megapotamica (Spreng.) Moldenke (Lamiaceae)
}

\author{
Nelson Luiz Cosmo ${ }^{1,5}$, Alessandra Mara Gogosz ${ }^{2}$, Antônio Carlos Nogueira ${ }^{3}$, Cleusa Bona ${ }^{4}$ e \\ Yoshiko Saito Kuniyoshi ${ }^{3}$
}

Recebido em 11/03/2008. Aceito em 11/08/2008

RESUMO - (Morfologia do fruto, da semente e morfo-anatomia da plântula de Vitex megapotamica (Spreng.) Moldenke (Lamiaceae)). Vitex megapotamica (tarumã) é espécie arbórea, decídua, com ocorrência, no Brasil, desde Minas Gerais até o Rio Grande do Sul. Visando à caracterização morfológica do fruto, da semente e morfo-anatômica da plântula, frutos desta espécie foram coletados e as sementes postas para germinar em laboratório. As plântulas foram coletadas desde a protrusão da raiz até o desenvolvimento do primeiro par de eofilo. Foram realizadas medições e pesagem de frutos, e contagem do número de sementes por frutos. As características morfológicas do fruto e da semente são aqui descritas e ilustradas, assim como a morfo-anatomia da plântula. O fruto é drupóide, nuculânio, tetralocular, contendo apenas uma ou duas sementes com fina camada de endosperma e embrião axial, foliáceo. O diásporo (pirênio) é constituído pelo endocarpo mais a semente. O endocarpo lenhoso parece exercer restrição sobre a germinação das sementes desta espécie. A plântula é epigea, fanerocotiledonar, com paracotilédones elípticos, com margem inteira, e eofilos opostos, simples, elípticos, com margem serreada, apresentando tricomas tectores. Tanto o paracotilédone quanto o eofilo apresentam mesofilo heterogêneo, dorsiventral, feixe colateral em forma de arco e estômatos anomocíticos. A raiz é poliarca, com córtex parênquimático; o hipocótilo possui tricomas glandulares e nãoglandulares, colo distinto, e com cerca de 20 dias encontra-se em início de crescimento secundário. Diversas das características da plântula de Vitex megapotamica estão relacionadas à sua condição de espécie heliófila.

Palavras-chave: anatomia vegetal, fruto, morfologia vegetal, plântula, semente

\begin{abstract}
Fruit and seed morphology and morpho-anatomy of seedlings of Vitex megapotamica (Spreng.) Moldenke (Lamiaceae)). Vitex Megapotamica (tarumã) is a deciduous tree occurring in Brazil from Minas Gerais to Rio Grande do Sul States. In order to characterize fruit and seed morphology and morpho-anatomy of seedlings, fruits of this species were collected and seeds were germinated in the laboratory. Seedlings were collected from root protrusion to development of the first pair of eophylls. The fruits were measured and weighed and the number of seeds per fruit counted. Fruit and seed morphology were described and illustrated, as well as morphoanatomy of the seedling. The fruit is a 4-locular drupe containing only one or two seeds with a thin layer of endosperm and an axial, foliate embryo. The woody endocarp seems to restrict germination in this species. The seedling has epigeal, phanerocotylar development; elliptical paracotyledons with entire margins, and opposite, simple, elliptical eophylls with serrate margins, and simple multicelullar trichomes. Paracotyledons and eophylls have heterogeneous dorsiventral mesophyll, collateral bundle, and anomocytic stomata. The root is polyarc, with parenchymatous cortex; the hypocotyl has glandular and non-glandular trichomes, a distinct collet, and within 20 days it starts secondary growth. Many characteristics of seedlings in V. megapotamica are related to the fact that it is a heliophyte.
\end{abstract}

Key words: fruit, plant anatomy, plant morphology, seed, seedling

\section{Introdução}

O gênero Vitex, pertencente à Lamiaceae de acordo com APG II (Souza \& Lorenzi 2005), compreende árvores e arbustos, com folhas decíduas, compostas, digitadas, com três a sete folíolos inteiros. As inflorescências são axilares, de coloração azul, roxa, branca ou amarela. Os frutos são drupáceos, com mesocarpo carnoso e endocarpo lenhoso, tetralocular, com quatro sementes (Troncoso 1973).

Vitex megapotamica (Spreng.) Moldenke é árvore decídua e heliófila, conhecida popularmente por tarumã. Os frutos são comestíveis e as folhas podem ser utilizadas na medicina popular. Ocorre desde o Estado

\footnotetext{
1 Universidade Federal do Paraná, Departamento de Ciências Florestais, Programa de Pós-Graduação em Engenharia Florestal

2 Universidade Federal do Paraná, Departamento de Botânica, Programa de Pós-Graduação em Botânica

3 Universidade Federal do Paraná, Departamento de Ciências Florestais, Rua Lothário Meissner 632, Bairro Jardim Botânico, 80210-170 Curitiba, PR, Brasil (nogueira@.ufpr.br)

4 Universidade Federal do Paraná, Departamento de Botânica, C. Postal 19031, 81531-980 Curitiba, PR, Brasil

5 Autor para correspondência: ncosmo@gmail.com
} 
de Minas Gerais até o do Rio Grande do Sul, sendo encontrada também no Uruguai, Paraguai e Argentina. Sua distribuição é bastante esparsa, tendo preferência por solos úmidos e profundos das planícies aluviais, e dos vales ou início das encostas (Reitz et al. 1983).

Frutos e sementes de diferentes táxons são freqüentemente muito contrastantes quanto à sua morfologia (Cutter 1987). Especialmente a variabilidade da estrutura da semente das angiospermas, e sua relativa constância em grupos menores, permitem utilizar os seus caracteres na identificação das espécies (Esau 1974). O reconhecimento de características morfológicas de frutos e sementes no interior da floresta constitui uma importante ferramenta para a identificação de espécies, além de servir de base para estudos que visem maiores conhecimentos referentes à germinação, armazenamento, teste de qualidade de sementes, entre outros (Amorim et al. 1997).

Portanto, é de grande relevância a realização de estudos que considerem em conjunto as características morfológicas de frutos e sementes, bem como dos estágios iniciais do desenvolvimento das plantas. Algumas espécies nativas foram estudas sob este aspecto por Kuniyoshi (1983), Araújo \& Matos (1991), Silva \& Matos (1991), Amorim et al. (1997), Ferreira et al. (1998), Souza \& Oliveira (2004), entre outros.

Segundo Kuniyoshi (1983), o acompanhamento da plântula em desenvolvimento permite diferenciar espécies muito semelhantes, constituindo um elemento adicional de identificação e auxiliando em estudos de regeneração. Além disso, alguns estudos têm relacionado as características morfológicas de plântulas a aspectos funcionais e fatores ecológicos do meio em que estas se desenvolvem, tais como os trabalhos de Vogel (1980), Wright et al. (2000), Ibarra-Manríquez et al. (2001), Ressel et al. (2004), entre outros.

Apesar dos frutos e sementes de muitas espécies nativas serem descritos na literatura, são relativamente poucos os trabalhos, diante da grande diversidade da flora brasileira, que abordam mais detalhadamente esses órgãos, sendo ainda mais raros os trabalhos com plântulas. Além disso, de acordo com Souza (2003), os estudos de morfologia de plântulas geralmente não incluem a análise estrutural de seus órgãos, o que dificulta, por exemplo, a compreensão do processo de estabelecimento da planta em um determinado ambiente.

O trabalho tem como objetivo caracterizar e ilustrar a morfologia dos frutos, sementes e a morfo-anatomia das plântulas de $V$. megapotamica, visando contribuir tanto para a botânica estrutural e taxonômica, como para a ecologia, além de permitir a identificação da espécie no campo.

\section{Material e métodos}

Frutos maduros de Vitex megapotamica foram coletados de seis matrizes, em abril/2006, nas proximidades do Campus do Centro Politécnico da Universidade Federal do Paraná (UFPR), Curitiba, PR, região da Floresta Ombrófila Mista. Após a coleta, os frutos foram beneficiados em laboratório, sendo deixados por 24 horas em saco plástico para o amolecimento da polpa, que foi posteriormente retirada macerando-se os frutos em peneira com areia grossa, uma vez que a polpa fica fortemente aderida ao pirênio (endocarpo + semente). Depois de separados da polpa, os pirênios foram deixados sobre jornal em local sombreado e ventilado por algumas horas para a secagem.

Utilizaram-se 50 unidades, tomadas aleatoriamente, para observação e ilustração do aspecto externo dos frutos e da morfologia do pirênio, que foi partido longitudinalmente e transversalmente com alicate de corte. Para a medição do fruto foram tomadas 100 unidades, sendo medidos com paquímetro o diâmetro do fruto e comprimento, largura e espessura do pirênio. Não foram medidas nem pesadas as sementes devido à dificuldade de retirá-las inteiras do pirênio. Para a pesagem foram separadas, logo após a coleta, oito amostras de 100 frutos cada. O mesmo procedimento foi repetido com os pirênios, depois que estes estavam enxutos. Para a contagem do número de sementes por fruto, 100 pirênios foram partidos transversalmente.

Visando acompanhar os estágios de crescimento da plântula, os diásporos foram plantados em vasos plásticos com substrato constituído de areia, terra preta e vermiculita (1:1:1), totalizando 8 vasos com 10 diásporos cada. Também foram plantados, da mesma maneira, 80 diásporos partidos longitudinalmente de forma que a semente ficasse parcialmente exposta.

Para a caracterização anatômica, as plântulas foram amostradas em várias fases, de 5 a 20 dias após a germinação. As amostras foram fixadas em FAA 50, posteriormente incluídas em polietileno e secionadas em micrótomo de rotação. Foram obtidas seções histológicas da região mediana do paracotilédone, do eofilo, do hipocótilo e da raiz, sendo coradas com fucsina básica $(0,5 \%)$ e azul de astra $(1 \%)$, em solução aquosa, e montadas de forma semi-permanente, utilizando-se gelatina glicerinada. Tais procedimentos de fixação, inclusão, coloração e montagem são revisados e descritos por Kraus \& Arduin (1997). Para a visualização de estômatos em vista frontal, foram retiradas porções da epiderme em ambas as faces do paracotilédone e do eofilo, utilizando-se pinça com ponta fina. Tais amostras foram montadas em lâminas com água. 
A descrição morfológica do fruto e da semente foi realizada com base nos trabalhos de Kuniyoshi (1983), Spjut (1994) e Barroso et al. (1999). Como apoio à caracterização morfo-anatômica da plântula foram consultados os trabalhos de Metcalfe \& Chalk (1979) e Vogel (1980).

Na observação e ilustração da morfologia dos frutos, sementes e plântulas foi utilizado microscópio estereoscópico, enquanto que a caracterização anatômica das plântulas foi realizada utilizando-se microscópio com câmara clara acoplada.

\section{Resultados e discussão}

Morfologia do fruto - Vitex megapotamica tem fruto esférico, de superfície lisa e brilhante (Fig. 1), verdeclaro quando imaturo, tornando-se roxo escuro na maturidade. O cálice é persistente e o fruto desprende-se do longo pedicelo, quando maduro. O diásporo é constituído pelo endocarpo mais a(s) semente(s), tendo dispersão zoocórica, especialmente pela avifauna.

O fruto, seguindo a classificação de Barroso et al. (1999), enquadra-se no tipo nuculânio, por apresentar pericarpo de consistência carnosa (Fig. 2A) e endocarpo lenhoso (pirênio) (Fig. 2B). Porém, considerando a revisão dos tipos de frutos realizada por Spjut (1994), nota-se que o termo nuculânio pode gerar confusão por ter sido utilizado por vários autores com diferentes definições. Portanto, prefere-se utilizar para o fruto de $V$. megapotamica o termo drupa, definido por Spjut (1994) como fruto com pericarpo carnoso com um ou mais de um pirênio.
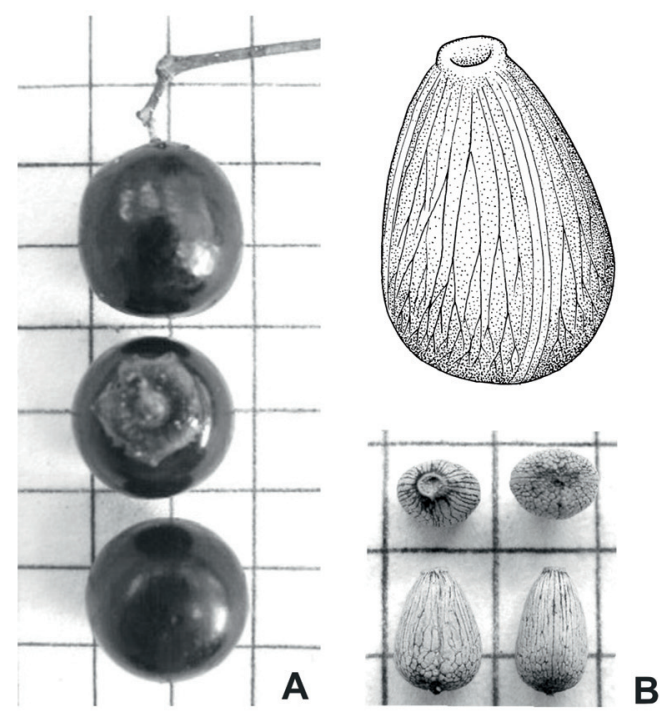

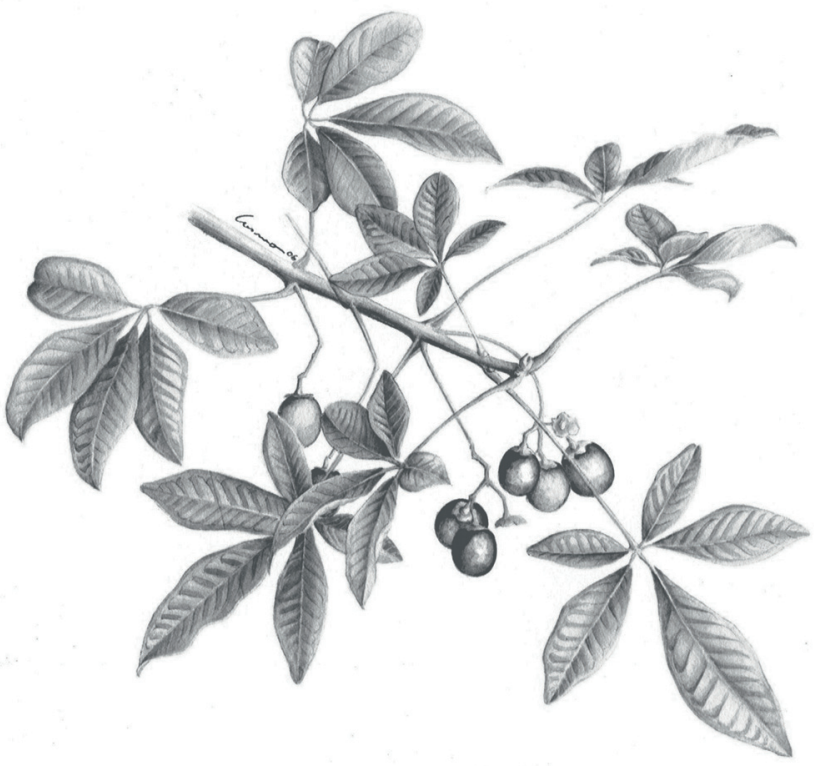

Figura 1. Ramo com frutos maduros de Vitex megapotamica (Spreng.) Moldenke (Lamiaceae).

O pirênio em $V$. megapotamica tem textura áspera e é dividido em quatro lóculos por suturas longitudinais pouco evidentes (Fig. 2C). Segundo McLean \& IvimeyCook (1956), em Lamiaceae o ovário é bicarpelar, porém, na maturidade, os carpelos separam-se em quatro unidades unisseminadas, com paredes duras, sendo cada um dos carpelos subdivididos por um falso septo, que se desenvolve secundariamente em relação ao septo verdadeiro.

$\mathrm{Na}$ contagem de sementes, $88 \%$ dos pirênios continham apenas uma semente desenvolvida, $8 \%$, duas,

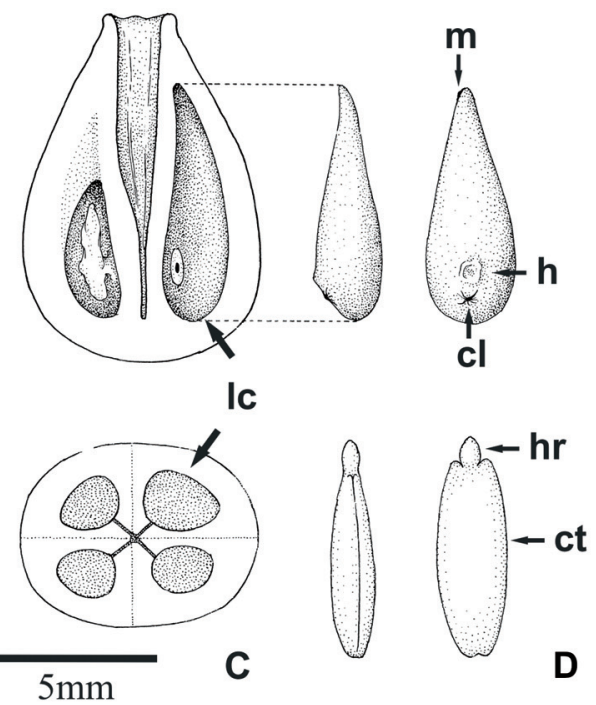

Figura 2. Morfologia do fruto, pirênio e semente de Vitex megapotamica (Spreng.) Moldenke (Lamiaceae). A. Aspecto externo do fruto. B. Pirênio. C. Secções longitudinal e transversal do endocarpo. D. Semente (acima), e embrião (abaixo), em vistas lateral e ventral. (cl: calaza, ct: cotilédones, h: hilo, hr: eixo hipocótilo-radicular, lc: lóculo, m: micrópila). 
e $4 \%$ deles possuíam apenas sementes atrofiadas, sendo que os lóculos que as continham eram geralmente menores que aqueles contendo sementes normais.

O fruto pesa em média $3,17 \mathrm{~g}$, com $17,66 \mathrm{~mm}$ diâm.; o pirênio pesa $0,35 \mathrm{~g}$, tendo $11,26 \mathrm{~mm}$ compr., $8,09 \mathrm{~mm}$ larg. e 6,71 mm espes. (Tab. 1).

Morfologia da semente - A semente, que ocupa todo o lóculo, é elipsóide, com tegumento papiráceo, testa áspera, cor bege-clara, com micrópila, hilo e calaza visíveis sob lupa. Troncoso (1973) classifica as sementes de Vitex como exalbuminosas, porém, observou-se no presente trabalho que uma fina camada de tecido de reserva permanece na semente madura de $V$. megapotamica, indicando que seria mais adequado classificar a semente desta espécie como albuminosa. O embrião é axial, foliáceo, espatulado, com eixo hipocótilo-radicular curto em relação aos cotilédones, que são aclorofilados neste estágio (Fig 2D).

Germinação - Constatou-se que a germinação teve uma distribuição temporal bastante irregular, sendo que muitas das sementes levaram de dois a três meses para germinarem, e algumas germinaram apenas após a passagem do período de inverno. Isto sugere a ocorrência de algum tipo de dormência, muito provavelmente associada à resistência imposta pelo endocarpo à emergência da raiz primária.

Das sementes contidas nos pirênios que foram partidos antes da semeadura, $70 \%$ germinaram em menos de 15 dias, enquanto nenhuma germinação foi observada nos vasos com pirênios intactos. No entanto, essas sementes não desenvolveram plântulas normais, devido à proliferação de fungos e a danos causados no embrião durante o corte dos pirênios.

Considerando que a dispersão dos diásporos ocorre pouco antes do inverno, a ocorrência de dormência poderia representar uma importante estratégia de sobrevivência das plântulas de V. megapotamica, uma vez que estas se estabeleceriam num período mais favorável. Além disso, segundo McLean \& Ivimey-Cook (1956), a presença de dormência propicia maior distribuição temporal e espacial da germinação, favorecendo a dispersão e sobrevivência da espécie pela diminuição da competição intra-específica.
Morfologia da plântula - A plântula tem desenvolvimento epígeo, fanerocotiledonar, possuindo "cotilédones" opostos, verdes e foliáceos. Estes, de acordo com Vogel (1980), são melhor definidos como paracotilédones, que são homólogos às duas primeiras folhas opostas da plântula, que através do aborto dos verdadeiros cotilédones obtiveram sua posição e a função de fornecimento de alimento para os processos vitais básicos às plântulas.

A emissão da raiz primária ocorre logo após a ruptura do endocarpo ao longo de suas suturas longitudinais (Fig. 3A-B). Os paracotilédones, que no início da emergência têm coloração amarelada, tornam-se gradativamente fotossintetizantes e expandem-se à medida que ocorre $\mathrm{o}$ crescimento do hipocótilo (Fig. 3C-D). Este tem coloração verde-clara, tricomas tectores visíveis sob lupa, e apresenta a região do colo mais espessa e mais clara. Os paracotilédones são glabros, elípticos, com base arredondada a truncada, ápice retuso e margem inteira. Logo após a abertura dos paracotilédones inicia-se o desenvolvimento dos eofilos, que são simples, elípticos, com base e ápice agudos e margem serreada (Fig. 3E).

O desenvolvimento da plântula se dá de forma relativamente rápida, sendo que em torno de 20 dias é possível observar todas as características aqui descritas e o início da fase de tirodendro, que, segundo Souza (2003), compreende o final do desenvolvimento do primeiro eofilo na plântula até o momento em que aparecem os primeiros nomofilos (metafilos), que, de acordo com Burger (1972) e Vogel (1980), são as folhas típicas da planta adulta.

Após a expansão do primeiro par de eofilos, inicia-se o desenvolvimento de novos pares cruzados de eofilos simples, com aspecto muito semelhante ao primeiro par. Em um experimento anterior observou-se que tirodendros desta espécie com dois anos de idade têm folhas compostas, digitadas, com margem serreada. Uma vez que a planta adulta tem nomofilos digitados, com margens inteiras (Reitz et al. 1983), nota-se uma considerável variação na forma das folhas durante o desenvolvimento da planta, fato este relevante para a identificação da espécie no campo nos primeiros estágios de desenvolvimento.

Tabela 1. Dimensões (mm) e peso (g) de fruto e pirênio de Vitex megapotamica (Spreng.) Moldenke (Lamiaceae).

\begin{tabular}{|c|c|c|c|c|c|c|}
\hline & \multicolumn{3}{|c|}{ Fruto } & \multicolumn{3}{|c|}{ Pirênio } \\
\hline & Diâmetro & Peso & Comprimento & Largura & Espessura & Peso \\
\hline Média & 17,66 & 3,17 & 11,26 & 8,09 & 6,71 & 0,35 \\
\hline Desvio padrão & 2,44 & 0,18 & 1,54 & 1,15 & 0,84 & 0,01 \\
\hline Coeficiente de variação (\%) & 13,84 & 5,70 & 13,64 & 14,21 & 12,57 & 4,41 \\
\hline
\end{tabular}



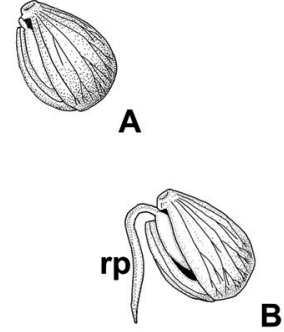

$10 \mathrm{~mm}$

B

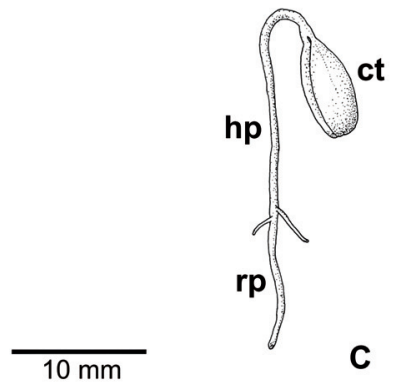

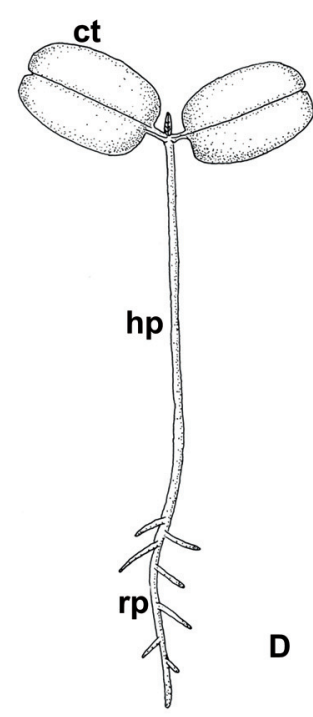

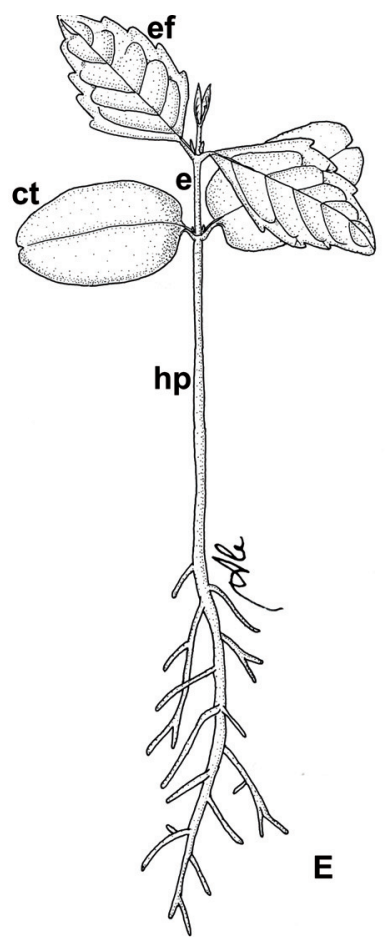

Figura 3. Estágios de desenvolvimento da plântula de Vitex megapotamica (Spreng.) Moldenke (Lamiaceae). A-E. Com 1, 3, 10 , 15 e 20 dias, respectivamente (e: epicótilo, ef: eofílo, hp: hipocótilo, pc: paracotilédone, rp: raiz primária).

O mesmo tipo de desenvolvimento dos eofilos foi observado por Burger (1972) em três espécies de Vitex (V. glabrata; V. quinata; V. pubescens), da flora asiática, sugerindo que esse seja um padrão normal de desenvolvimento, que pode ser freqüente no gênero. Seqüências características de eofilo ocorrem também, segundo Ducke (1969), em Anacardiaceae, Bignoniaceae, Fabaceae, Meliaceae, Mimosaceae, Sapindaceae, dentre outras, e, provavelmente, em muitas plântulas de espécies com nomofilos compostos.

De acordo com Cutter (1987), muitas espécies podem apresentar desenvolvimento heteroblástico, uma alteração na forma da folha com a idade, muitas vezes associada aos diferentes estados nutricionais da planta em crescimento.

Diversas das características morfológicas da plântula de $V$. megapotamica coincidem com sua condição de espécie heliófila. Dentre elas estão o desenvolvimento epígeo, fanerocotiledonar, e a presença de paracotilédones, que possibilitam um rápido estabelecimento da plântula em ambientes com alta incidência de luz (Vogel 1980; Wright et al. 2000; Ressel et al. 2004). A combinação destes caracteres, segundo Ibarra-Manríquez et al. (2001), é muito comum entre as espécies que dependem da abertura de clareiras para seu estabelecimento.

Anatomia da plântula-A raiz de V. megapotamica (Fig. 4) apresenta epiderme unisseriada, córtex parenquimático com exoderme pouco diferenciada e endoderme com estrias de Caspary. Em plântulas com cinco dias de idade observou-se que a medula parenquimática se estende até a região mediana da raiz primária (Fig. 4A-B). Em geral ocorrem quatro feixes de xilema primário, com disposição exarca (Fig. 4C), porém este número pode variar até seis. Em plântulas com cerca de 20 dias, a raiz principal encontra-se em início de crescimento secundário, evidenciado pela instalação do câmbio (Fig. 4D).

O hipocótilo (Fig. 5) tem epiderme unisseriada e córtex formado por parênquima. Observando este órgão em plântulas com cerca de 10 dias nota-se que, junto à periferia da medula parenquimática, os pólos de protoxilema e metaxilema são dispostos mais ou menos lateralmente um em relação ao outro, não se organizando nem da forma típica de caule (endarco), nem como raiz (exarco) (Fig. 5A-B). De acordo com Souza (2003), isto é típico em plântulas, uma vez que o hipocótilo constitui uma zona de transição entre caule e raiz.

Assim como a raiz, o hipocótilo em plântulas com 20 dias (Fig. 5) está em início de crescimento secundário, podendo-se observar elementos de xilema secundário e floema (Fig. 5C-D). Nesta fase também ocorrem faixas descontínuas de fibras associadas ao floema, na periferia do cilindro vascular (Fig. 5D). Na epiderme do hipocótilo ocorrem tricomas simples, glandulares e não-glandulares (Fig 5E-G), especialmente próximos à região do nó. 
O paracotilédone tem epiderme unisseriada em ambas as faces, mesofilo dorsiventral, formado por uma a duas camadas de parênquima paliçádico, com células em forma de cone invertido, e cerca de dez camadas de parênquima lacunoso (Fig. 6A). A nervura central é pouco saliente na face abaxial e possui um feixe colateral envolto pelas células de parênquima do mesofilo (Fig. 6B).
Estômatos anomocíticos (Fig. 6E) são presentes em ambas as faces do limbo (folha anfiestomática), aparentemente menos frequientes na face adaxial.

De acordo com Smith et al. (1997), diversos estudos têm evidenciado que a presença de estômatos em ambas as superfícies foliares aumentam consideravelmente o suprimento de dióxido de carbono
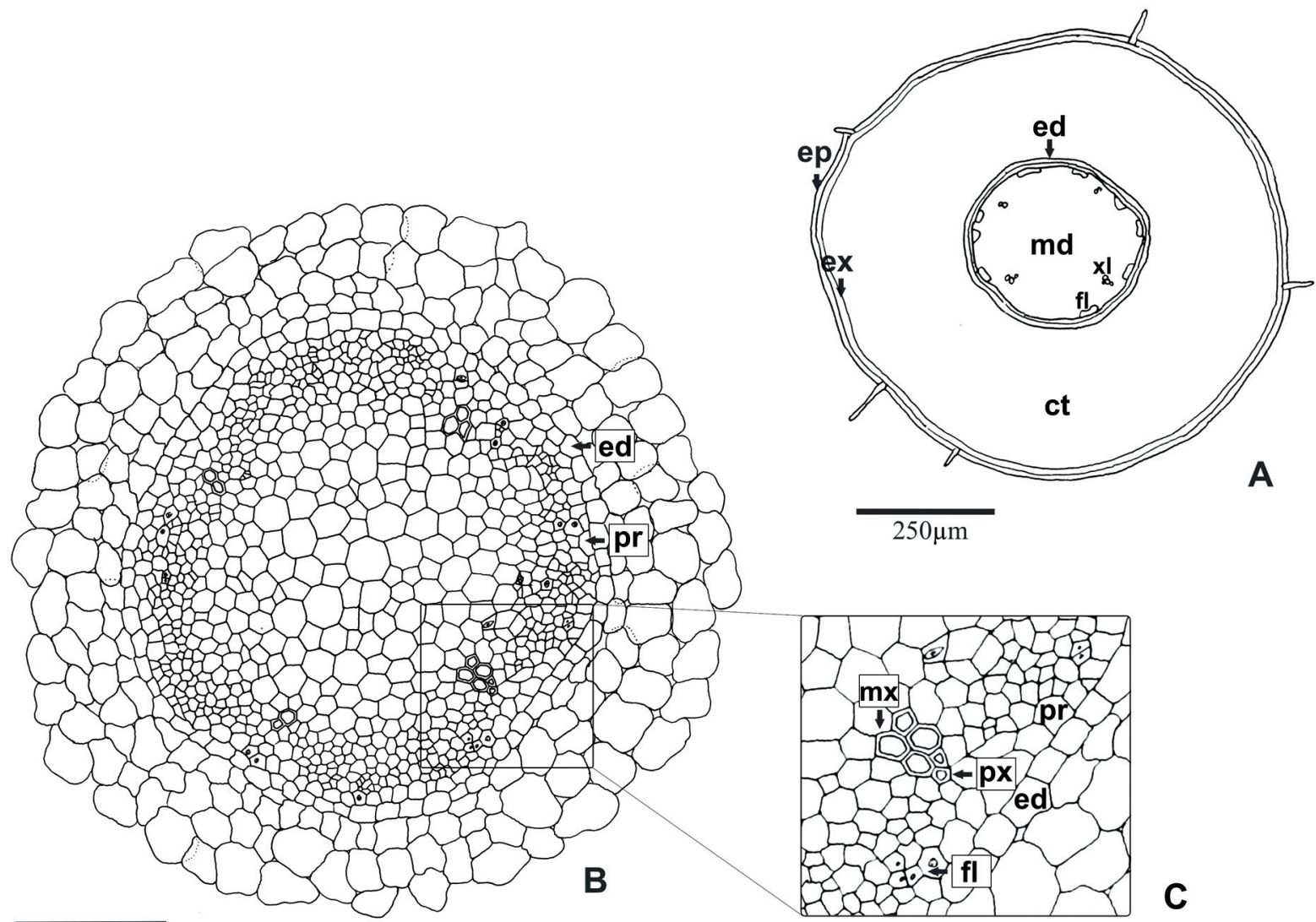

$250 \mu \mathrm{m}$

$100 \mu \mathrm{m}$

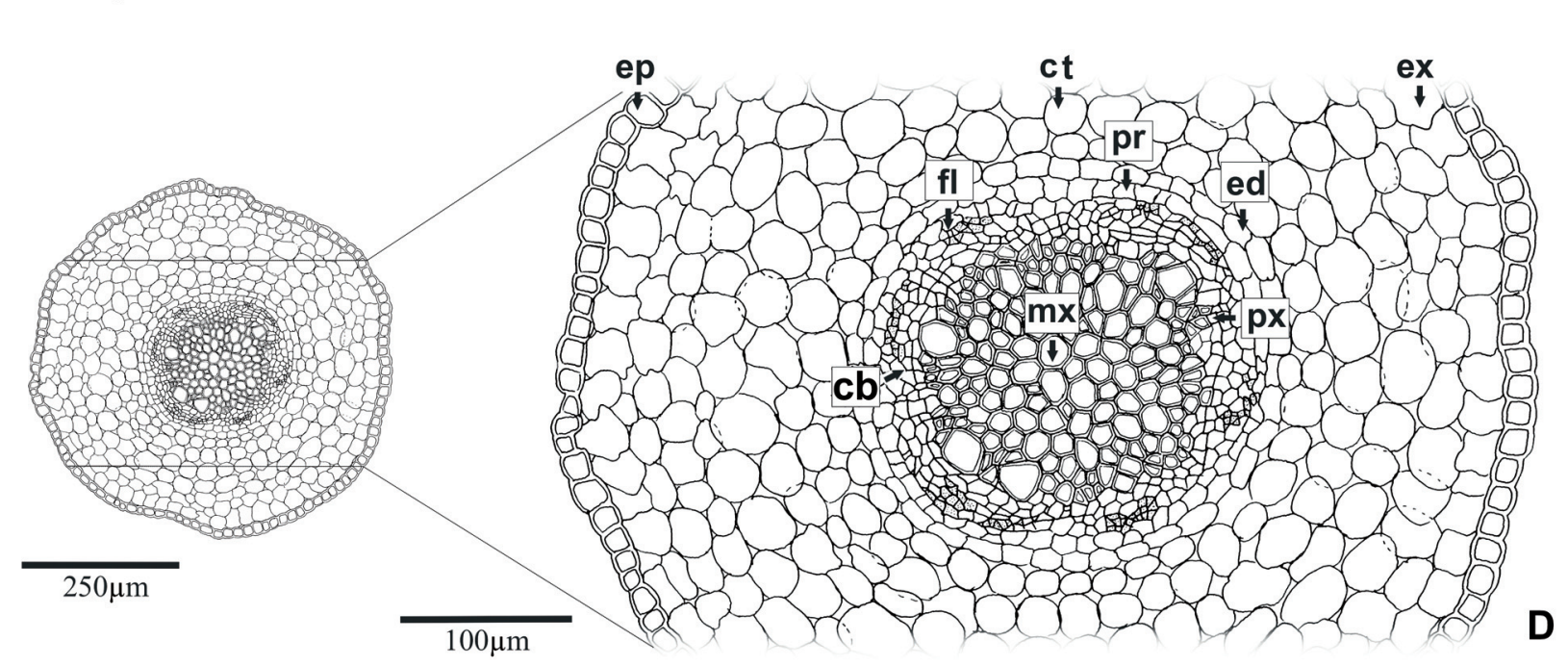

$100 \mu \mathrm{m}$

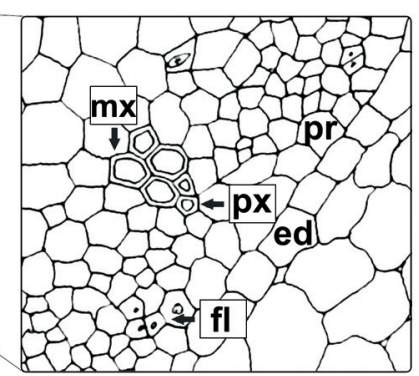

C

Figura 4. Secções transversais da raiz da plântula de Vitex megapotamica (Spreng.) Moldenke (Lamiaceae) A. Representação esquemática da região mediana da raiz em plântula com cinco dias; B. Detalhe da região do cilindro vascular; C. Detalhe do feixe vascular; D. Vista geral e detalhe de seção a $1 \mathrm{~cm}$ do ápice da raiz de plântula com 20 dias, em início de crescimento secundário (cb: câmbio, ct: região do córtex, ed: endoderme, ep: epiderme, ex: exoderme, fl: floema, md: medula, mx: metaxilema, pr: periciclo, px: protoxilema, xl: xilema). 
para as células do mesofilo, de modo a suportar maiores taxas fotossintéticas por unidade de área foliar.

No eofilo a epiderme também é unisseriada em ambas as faces e o mesofilo é heterogêneo dorsivental, constituído de uma camada de parênquima paliçádico (com células de formato semelhante às do paracotilédone) e de três a quatro de lacunoso (Fig. 6C). A nervura central, proeminente na face abaxial (Fig. 6C), é composta por um feixe colateral em forma de arco, circundado por parênquima fundamental e

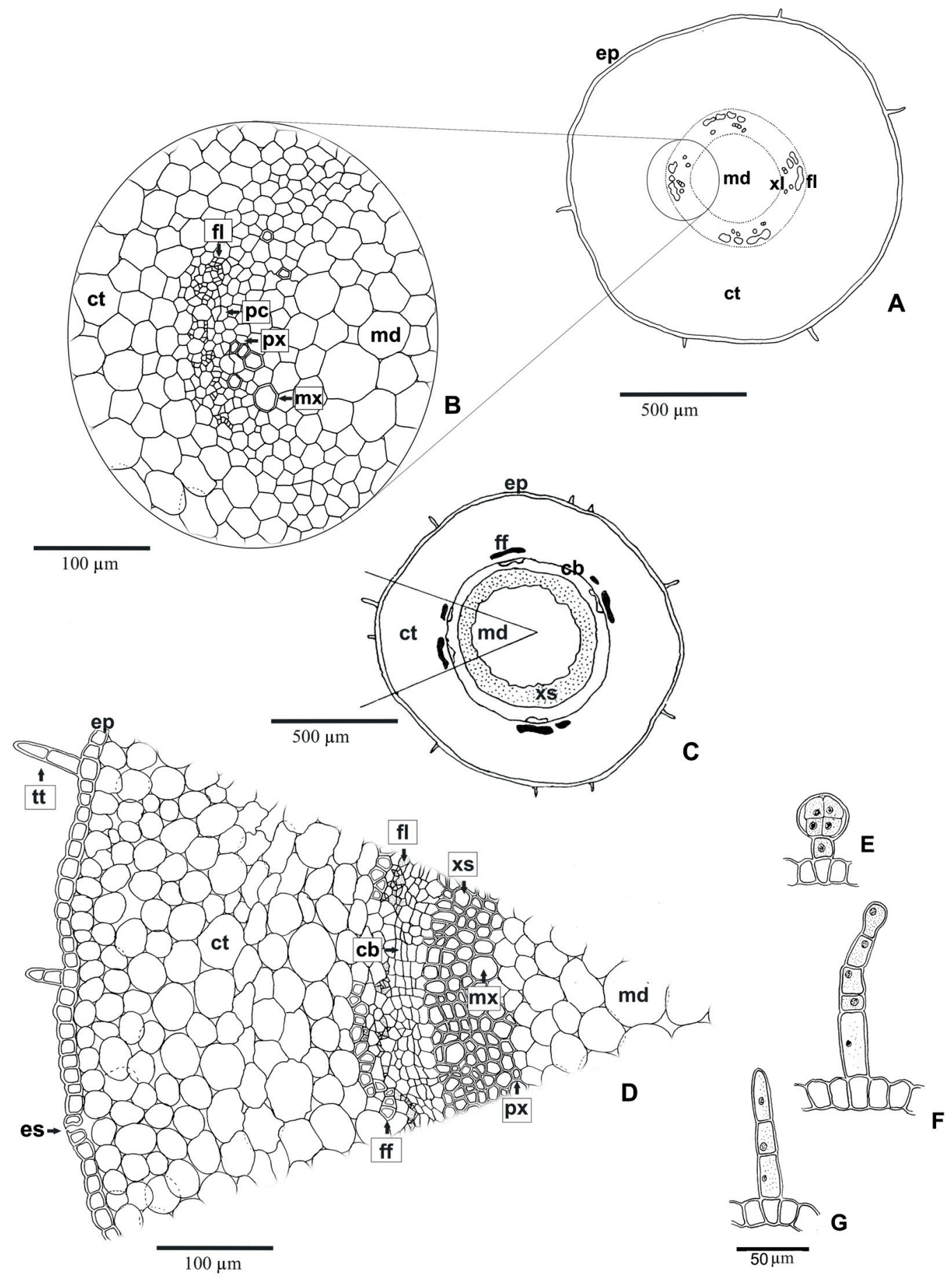

Figura 5. Secções transversais do hipocótilo de Vitex megapotamica (Spreng.) Moldenke (Lamiaceae). A. Esquema geral do hipocótilo em crescimento primário. B. Detalhe da região do feixe vascular, em plântula com 10 dias. C. Esquema do hipocótilo em início do crescimento secundário, em plântula com 20 dias. D. Detalhe. E-F. Tricomas glandulares no hipocótilo. G. Tricoma tector (cb: câmbio, ct: córtex, es: estômato, ff: fibras do floema, fl: floema, md: medula, mx: metaxilema, pc: procâmbio, px: protoxilema, tt: tricoma tector, xl: xilema primário, xs: xilema secundário). 
limitado por uma faixa de esclerênquima perivascular, na região abaxial (Fig. 6D). Ocorrem estômatos anomocíticos na face abaxial (Fig. 6F), ligeiramente proeminentes, e tricomas tectores simples, multisseriados (2-4 células) (Fig. 6G). Estes concentrados principalmente nas regiões das nervuras e das margens do limbo.

Nota-se que as células epidérmicas na face abaxial do eofilo possuem paredes anticlinais mais sinuosas que as do paracotilédone (Fig. 6E-F), e que o parênquima lacunoso no eofilo é mais estreito e parece ter espaços mais amplos (Fig. 6C). É importante observar, também, que ocorre uma considerável diferença na espessura total do limbo entre o eofilo e o paracotilédone, sendo este aproximadamente quatro vezes mais espesso que o eofilo (Fig. 6A, C). Segundo Smith et al. (1997), a ocorrência de lâminas foliares mais espessas está geralmente relacionada a folhas submetidas à alta intensidade luminosa e tanto a distribuição do estômato em ambas as faces do limbo, quanto a maior área celular do mesofilo, contribuem para altas taxas de fotossíntese em folhas de sol.
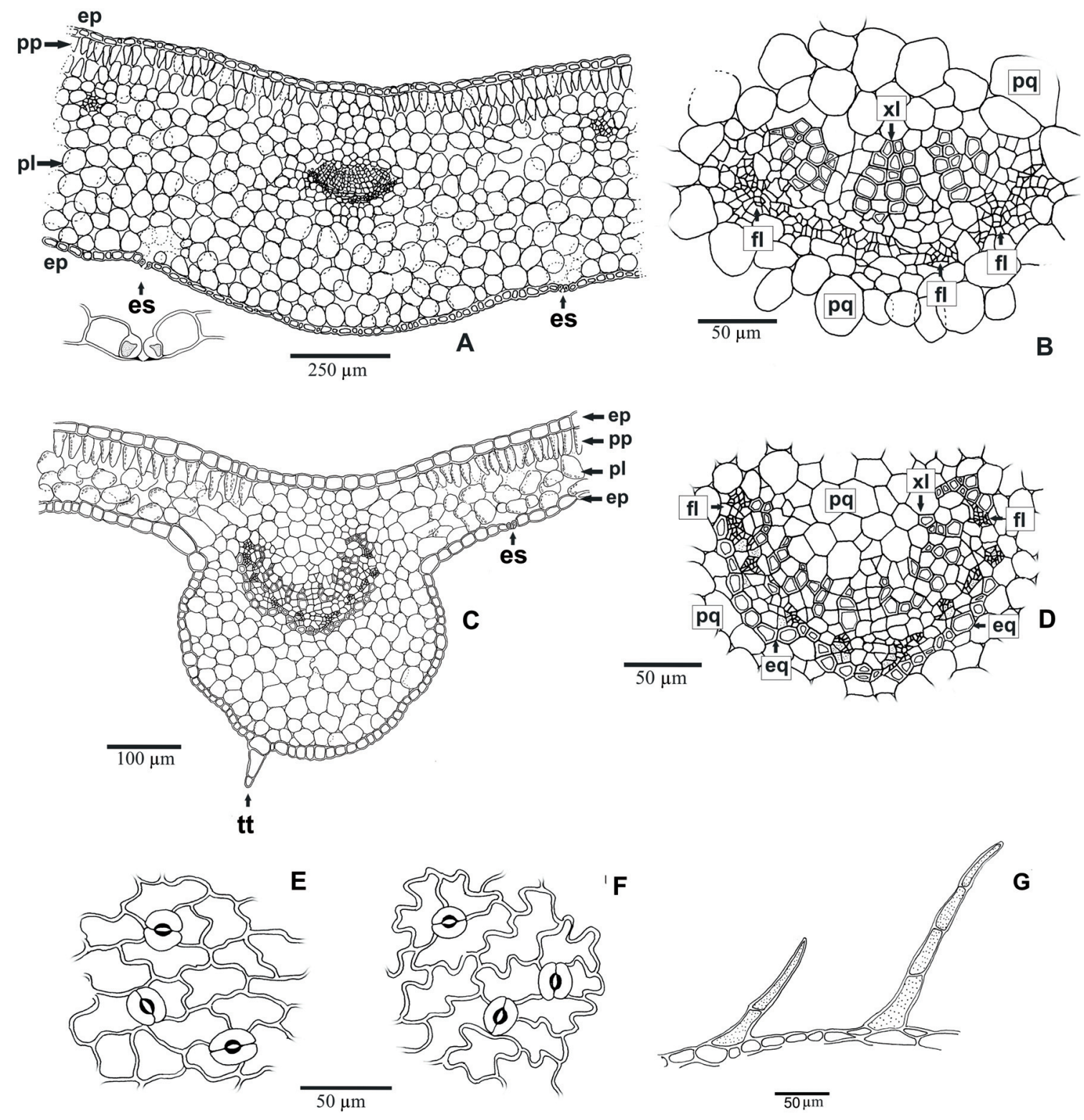

Figura 6. Secções transversais e paradérmicas do paracotilédone e do eofilo da plântula de Vitex megapotamica (Spreng.) Moldenke (Lamiaceae) com 20 dias. A-B. Vista geral e detalhe do feixe vascular do paracotilédone. C-D. Vista geral e detalhe do feixe vascular do eofilo. E-F. Epiderme na face abaxial do paracotilédone e eofilo, respectivamente, evidenciando a ocorrência de estômatos anomocíticos. G. Tricomas tectores na margem do eofilo (ep: epiderme, es: estômato, fl: floema, pl: parênquima lacunoso, pp: parênquima paliçádico, pq: parênquima fundamental, $\mathrm{tt}$ : tricoma tector, $\mathrm{xl}$ : xilema). 
Além disso, nota-se que o feixe vascular do paracotilédone tem uma estrutura mais simples, quando comparado ao do eofílo, representando um menor investimento da plântula no início do seu desenvolvimento. Isto faz sentido, considerando-se que a plântula nesta fase tem a sua disposição poucos recursos energéticos, e que o paracotilédone é um órgão relativamente efêmero.

Essas características, entre outras, devem propiciar ao paracotilédone de $V$. megapotamica o aparato necessário para uma eficiente sustentação do crescimento inicial da plântula, e para o seu estabelecimento, especialmente em ambientes ricos em luz, tais como as clareiras das formações secundárias onde a espécie ocorre.

A ocorrência dos tricomas no hipocótilo, epicótilo e eofilos, provavelmente deve também ter implicações na auto-ecologia da espécie. Diversos trabalhos têm abordado a função dos tricomas na defesa da planta contra herbivoria (Theobald et al. 1979; Cutter 1987; Paleari \& Santos 1998) e sua interferência no processo de fotossíntese devido a alterações na luz absorvida, regulação da temperatura foliar e redução da evapotranspiração (Smith et al. 1997). Além disso, a prevalência de diferentes tipos de tricomas está frequentemente relacionada à evolução dos grupos taxonômicos, o que tem sido mostrado em estudos sistemáticos comparativos das angiospermas (Theobald et al. 1979).

Diversas das características analisadas podem subsidiar o reconhecimento da planta no campo, além de auxiliar em estudos morfo-anatômicos e de ecologia. Alguns aspectos poderiam ser investigados em trabalhos futuros, como a possível ocorrência de dormência das sementes de Vitex megapotamica e as variações na morfologia das folhas ao longo do desenvolvimento da planta.

\section{Referências bibliográficas}

Amorim, I.L.; Dadive, A.C. \& Chaves, M.M.F. 1997. Morfologia do fruto e da semente, e germinação da semente de Trema micrantha (L.) Blum. Cerne 4: 129-142

Araújo, S.S. \& Matos, V.P. 1991. Morfologia da semente e de plântulas de Cassia fistula L. Revista Árvore 15: 217-223.

Barroso, G.M.; Morim, M.P.; Peixoto, A.L. \& Ichaço, C.L.F. 1999 Frutos e sementes: morfologia aplicada à sistemática de dicotiledôneas. Viçosa, UFV.

Burger, Hzn. 1972. Seedlings of some tropical trees and shrubs mainly of South East Asia. Wageningen, PUDOC.

Cutter, E.G. 1987. Anatomia Vegetal: órgãos, experimento interpretações. São Paulo, Roca. v.II.
Ducke, J.A. 1969. Seeds, seedlings, systems and systematic. Annals of the Missouri Botanical Garden 55: 125-161.

Esau, K. 1974. Anatomia das plantas com sementes. São Paulo, Edgard Blücher LTDA.

Ferreira, R.A.; Botelho, S.A.; Davide, A.C. \& Malavasi, M.M. 1998. Caracterização morfológica de fruto, semente, plântula e muda de Dipteryx alata Vogel - Baru (Leguminosae Papilionoideae). Cerne 4: 3-87.

Ibarra-Manríquez, G.; Ramos, M.M. \& Oyama, K. 2001. Seedling functional types in a lowland rain forest in Mexico. American Journal of Botany 88: 1801-1812.

Kraus, J.P. \& Arduin, M. 1997. Manual básico de métodos em morfologia vegetal. Seropédica: EDUR.

Kuniyoshi, Y.S. 1983. Morfologia da semente e da germinação de 25 espécies arbóreas de uma floresta de araucária. Curitiba, UFPR.

McLean, R.C. \& Ivimey-Cook, W.R. 1956. Textbook of Theoretical Botany. London. v.II.

Metcalfe, C.R. \& Chalk,L. 1979. Anatomy of the dicotyledons: systematic anatomy of leaf and stem, with a brief history of the subject. Oxford, Clarendon Press. v.I.

Paleari, L.M. \& Santos, F.A.M. 1998. Papel do indumento piloso na proteção contra a herbivoria em Miconia albicans (Melastomataceae). Revista Brasileira de Biologia 58: 151-157.

Reitz, R.; Klein, R.M. \& Reis, A. 1983. Projeto Madeira do Rio Grande do Sul. Itajaí, SUDESUL.

Ressel, K.; Guilherme, F.A.G.; Schiavini, I. \& Oliveira, P.E. 2004. Ecologia morfofuncional de plântulas de espécies arbóreas da Estação Ecológica do Panga, Uberlândia, Minas Gerais. Revista Brasileira de Botânica 27: 311-323.

Silva, L.M.M. \& Matos, V.P. 1991. Morfologia da semente e da germinação de Erythrina velutina Willd. Revista Árvore 15: 137-143.

Smith, W.K.; Vogelmann, T.C.; DeLucia E.H.; Bell, D.T. \& Shepherd, K.A. 1997. Leaf Form and Photosynthesis. Bio Science 47: 785-793

Souza, L.A. 2003. Morfologia e anatomia vegetal: célula, tecidos, órgãos e plântula. Ponta Grossa, Editora UEPG.

Souza, L.A. \& Oliveira, J.H.G. 2004. Morfologia e anatomia das plântulas de Tabebuia avellanedae Lor. Ex Griseb e T. chrysotricha (Mart. ex Dc.) Standl. (Bignoniaceae). Acta Scientiarum. Biological Sciences 26: 217-226.

Souza, V.C. \& Lorenzi H. 2005. Botânica Sistemática: guia ilustrado para identificação das famílias da Angiospermas da flora brasileira, baseado em APGII. Nova Odessa, Instituto Plantarum.

Spjut, W.R. 1994. A systematic treatment of fruit types. New York, The New York Botanical Garden.

Theobald, W.L.; Krahulik, J.L. \& Rollins, R.C. 1979. Trichome description and classification. Pp. 40-53. In: C.R. Metcalfe \& L. Chalk (eds.). Anatomy of the dicotyledons. sistematic anatomy of leaf and stem, with a brief store of the subject. Oxford, Clarendon Press. v.I.

Troncoso, N.S. 1973. Los géneros de Verbenáceas. Darwiniana 18: 393-395.

Vogel, E.F. 1980. Seedlings of dicotyledons: structure, development, types: descriptions of 150 woody Malesian taxa. Wageningen, Centre for Publishing and Documentation.

Wright, I.J.; Clifford, H.T.; Kidson, R.; Reed, M.L.; Rice, B.L. \& Westoby, M. 2000. A survey of seed and seedling characters in 1744 Australian dicotyledon species: cross-species trait correlations and correlated trait-shifts within evolutionary lineages. Biological Journal of the Linnean Society of London 69: 521-547. 